\title{
Achocolatados: análise química
}

\author{
Mércia de Freitas Eduardo*, Suzana Caetano da Silva Lannes
}

Departamento de Tecnologia Bioquímico-Farmacêutica, Faculdade de Ciências Farmacêuticas, Universidade de São Paulo

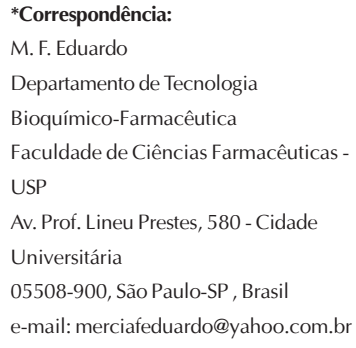

\begin{abstract}
Neste trabalho avaliaram-se propriedades quimicas de achocolatados do mercado brasileiro, sendo estas os teores de lipídios, proteinas, cinzas, umidade, $\mathrm{pH}$, teobromina e alcalóides totais. Estas propriedades são influenciadas principalmente pelo conteúdo de cacau em pó e pelo conteúdo dos ingredientes lácteos, como o leite em pó e o soro de leite em pó. Foi feito um comparativo entre as marcas de achocolatados, dando ênfase às grandes diferenças, quando existentes, entre os achocolatados dietéticos (para dietas de restrição de sacarose, frutose e glicose (dextrose)) e "light" (com redução de açúcares) e os tradicionais.
\end{abstract}

\section{Unitermos:}

- Achocolatados

- Informações nutricionais

- Propriedades químicas

\section{INTRODUÇÃO}

Os achocolatados são alimentos consumidos por pessoas de todas as idades e podem ser encontrados em todo o mundo. As suas características sensoriais e nutricionais, assim como sua conveniência e praticidade, fazem com que o produto seja bem aceito pelo consumidor.

$\mathrm{Na}$ sua apresentação mais simples, o achocolatado contém cerca de $70 \%$ de sacarose ou de outros açúcares e cerca de 30\% de cacau em pó (Varnam, Sutherland, 1997).

Aos achocolatados pode-se incorporar leite em pó para conseguir um produto completo e realmente instantâneo. Normalmente, não se recomenda o uso de leite em pó integral, devido a alterações oxidativas, que limitam a vida útil do produto (Varnam, Sutherland, 1997). Outros ingredientes típicos usados na formulação de achocolatados comerciais incluem extrato de malte, açúcar e glicose, vitaminas e sais minerais como suplementos (Omobuwajo et al., 2000). Fortificação de achocolatados com sais de ferro (fumarato ferroso, sulfato ferroso, pirofosfato férrico) vem sendo realizada com o intuito de diminuir o índice de anemia em crianças e adolescentes (Hurrel et al., 1991).
Como esses produtos vêm sendo amplamente consumidos, muitas indústrias têm produzido achocolatados, fazendo com que haja grande variedade e preços competitivos ao consumidor. Porém, o processamento, os ingredientes e as concentrações utilizadas não são os mesmos, fazendo com que haja grande variação nas suas propriedades nutricionais, tais como teor de lipídios, proteínas, carboidratos, teobromina e outros alcalóides, entre outros.

Nos dias de hoje, o consumidor vem mostrando cada vez mais preocupação em relação à sua alimentação. Pesquisas demonstram a importância da diminuição da ingestão de lipídios e açúcares e do aumento da ingestão de proteínas e carboidratos complexos (Cândido,Campos, 1996), bem como alertam quanto ao consumo indiscriminado de produtos contendo alcalóides, como por exemplo a teobromina. Ela está presente, em sua maior parte, nos chocolates e derivados (achocolatados, bebidas achocolatadas, biscoitos de chocolate, entre outros) e sabe-se que esta, similarmente à cafeína e outros alcalóides, atua como estimulante do sistema nervoso central e do músculo cardíaco. O seu consumo moderado pode melhorar o desempenho no trabalho e nos estudos, 
mas a alta ingestão pode causar irritabilidade, insônia e distúrbios gastrointestinais (Caffeine...1979). Por um outro lado, existe uma especulação de que dieta rica em polifenóis (presentes no cacau) poderia proteger o sistema cardiovascular devido à ação antioxidante direta ou devido à ação anti-trombótica (Rein et al., 2000; Ying et al., 2001; Ninfali et al., 2002).

Devido a esta preocupação do consumidor em relação à sua dieta, o hábito de ler as informações nutricionais nos rótulos dos produtos industrializados vem sendo cada vez mais freqüente, havendo a necessidade de que estas informações sejam corretas e completas.

\section{MATERIAL E MÉTODOS}

\section{Material}

Foram analisadas 11 marcas comerciais de achocolatados, sendo elas: Chocolike, Achocolatado Extra,
Garotada, Gold, Leo, Moc, Nescau, Nescau light, Nesquik, Sempre light e Toddy.

Os achocolatados Gold e Sempre light são dietéticos (especialmente formulados para atender às necessidades de pessoas com distúrbios no metabolismo de sacarose, frutose e/ou glicose (dextrose)), o Nescau light é considerado "light", ou seja, com redução calórica devido à redução de açúcar (Brasil, 2004), e os demais são tradicionais. Neste trabalho, será usado o termo genérico dietético para designar os achocolatados Gold e Sempre light e o termo genérico "light" para designar o achocolatado Nescau light.

A Tabela I mostra os ingredientes dos achocolatados.

\section{Métodos}

Extração e determinação do teor de lipídios totais

A extração e determinação foram feitas através de extração em aparelho de Soxhlet com éter de petróleo (Schetty et al., 1969 - método 36 C/04, citados por Lannes, 1997).

TABELA I - Ingredientes dos achocolatados, conforme declarado no rótulo.

\begin{tabular}{|c|c|c|}
\hline Marca do achocolatado & Fabricante & Ingredientes \\
\hline Chocolike & Cinalp & $\begin{array}{l}\text { Açúcar, cacau solubilizado, leite em pó desnatado, complexo } \\
\text { vitamínico, soro de leite, lecitina de soja e aroma imitação baunilha }\end{array}$ \\
\hline Achocolatado Extra & Cinalp & $\begin{array}{l}\text { Açúcar, cacau solubilizado, leite em pó desnatado, complexo } \\
\text { vitamínico, soro de leite, lecitina de soja e aroma imitação de baunilha }\end{array}$ \\
\hline Garotada & Garoto & $\begin{array}{l}\text { Açúcar, cacau em pó solubilizado, complexo vitamínico, leite em pó } \\
\text { desnatado, soro de leite em pó, lecitina de soja e aromatizantes }\end{array}$ \\
\hline Gold & Vepê & $\begin{array}{l}\text { Maltodextrina, cacau lecitinado, leite desnatado em pó, soro de leite, } \\
\text { edulcorantes artificiais: ciclamato de sódio, aspartamo, } \\
\text { acessulfamo-k e sacarina sódica; aromatizante e antiumectante: } \\
\text { dióxido de silício }\end{array}$ \\
\hline Leo & Maxul & $\begin{array}{l}\text { Sacarose, cacau em pó, maltodextrina, estabilizante lecitina de soja, } \\
\text { aroma de baunilha, chocolate e caramelo }\end{array}$ \\
\hline Moc & Mococa & $\begin{array}{l}\text { Açúcar, cacau, maltodextrina, sal, vitaminas, estabilizante lecitina } \\
\text { de soja e aromatizante }\end{array}$ \\
\hline Nescau & Nestlé & $\begin{array}{l}\text { Açucar, cacau em pó, maltodextrina, vitaminas, minerais, } \\
\text { aromatizantes e emulsificante lecitina de soja }\end{array}$ \\
\hline Nescau light & Nestlé & $\begin{array}{l}\text { Açúcar, cacau em pó, maltodextrina, leite em pó desnatado, } \\
\text { vitaminas, emulsificante lecitina de soja, edulcorantes artificiais } \\
\text { acessulfamo de potássio e ciclamato e aromatizantes }\end{array}$ \\
\hline Nesquik & Nestlé & Açúcar, cacau em pó, vitaminas, sal, emulsionante \\
\hline Sempre light & Nutrilatina & $\begin{array}{l}\text { Cacau em pó, maltodextrina, soro de leite, leite desnatado, } \\
\text { estabilizante, estabilizante carragena, aromas naturais de baunilha } \\
\text { e chocolate e edulcorante artificial aspartamo }\end{array}$ \\
\hline Toddy & Quaker & $\begin{array}{l}\text { Açúcar, cacau, extrato de malte, sal, leite em pó desnatado, soro de } \\
\text { leite em pó, vitaminas, lecitina de soja e aromatizantes }\end{array}$ \\
\hline
\end{tabular}




\section{Proteína}

A análise foi efetuada através do equipamento Micro Kjeldahl, utilizando-se aproximadamente $0,4 \mathrm{~g}$ de amostra, $1,5 \mathrm{~g}$ de mistura catalítica de sulfato de cobre e sulfato de potássio (1:9) e $3 \mathrm{~mL}$ de ácido sulfúrico concentrado. O fator de conversão utilizado foi de 6,25 (Instituto Adolfo Lutz, 1976).

\section{Cinzas}

Foi efetuada análise segundo metodologia do Instituto Adolfo Lutz (1976), utilizando-se cerca de $2 \mathrm{~g}$ de amostra

\section{Umidade}

Pesou-se cerca de $10 \mathrm{~g}$ de amostra em cápsula de porcelana tarada. Levou-se à estufa a $105^{\circ} \mathrm{C}$, onde o material foi dessecado até peso constante.

$\mathrm{pH}$

Pesou-se $10 \mathrm{~g}$ da amostra e transferiu-se a amostra para erlenmeyer seco, com o auxílio de $100 \mathrm{~mL}$ de água destilada a $25^{\circ} \mathrm{C}$. Agitou-se o conteúdo do frasco até que as partículas ficassem uniformemente suspensas. Deixouse em repouso por 10 minutos e transferiu-se o líquido sobrenadante para frasco seco e imediatamente determinou-se o pH com um pHmetro HD 8602 (Delta Ohm) (Instituto Adolfo Lutz, 1976).

\section{Teobromina e alcalóides totais}

A determinação de teobromina e alcalóides totais foi feita através da técnica espectrofotométrica, em espectofotômetro UV-1203 (Shimadzu), com leituras no espectro UV em 272 nm (máx) e 306 nm (Schetty et al., 1969 - método 36C/17, Lannes, 1997).

\section{RESULTADOS E DISCUSSÃO}

\section{Lipídios totais}

A determinação direta de lipídios em alimentos, feita pela extração com solventes adequados, seguida de sua remoção, denomina-se, na realidade, determinação do extrato etéreo deste alimento, por representar não somente o teor de lipídios, mas também o teor de vários compostos como carotenóides, vitaminas lipossolúveis (A, D, E e K), esteróis, óleos essenciais e outros, os quais são geralmente extraídos pelo solvente, nas condições do método (Carvalho et al., 1990; Eduardo, Bavutti, 2002). A maior parte da gordura dos achocolatados provém do cacau e derivados e do leite.

A Tabela II mostra o teor de lipídios totais dos achocolatados analisados e o teor de lipídios declarado nos rótulos.

O teor de lipídios variou significativamente entre as diferentes marcas de achocolatados, mostrando maior teor nos produtos dietéticos e "light", sendo que, provavelmente, este teor seja proveniente do cacau em pó, já que a análise de teobromina sugere conteúdo bem maior do cacau para estas amostras. De acordo com Cândido e Campos (1996), a sacarose ajuda a dar corpo ao alimento e como estes achocolatados apresentam nenhuma ou pouca sacarose, eles precisam de quantidade maior de cacau em pó (além da maltodextrina) para aumentar o corpo, o que faz aumentar o seu teor lipídico.

TABELA II - Teor de lipídios dos achocolatados e o declarado nos rótulos

\begin{tabular}{lcc}
\hline Achocolatado & $\begin{array}{c}\text { Teor de lipídios (\%)* } \\
\text { (média } \pm \text { desvio-padrão) }\end{array}$ & $\begin{array}{c}\text { Teor de lipídios } \\
\text { declarado nos rótulos (\%) }\end{array}$ \\
\hline Chocolike & $1,63 \pm 0,11$ & 4,00 \\
Achocolatado Extra & $1,96 \pm 0,06$ & 4,00 \\
Garotada & $1,75 \pm 0,09$ & 2,00 \\
Gold & $5,93 \pm 0,17$ & 5,55 \\
Leo & $0,88 \pm 0,09$ & 0,00 \\
Moc & $1,51 \pm 0,05$ & 0,00 \\
Nescau & $2,18 \pm 0,16$ & 2,00 \\
Nescau light & $3,03 \pm 0,18$ & 0,00 \\
Nesquik & $2,24 \pm 0,14$ & 2,00 \\
Sempre light & $4,44 \pm 0,13$ & 5,42 \\
Toddy & $0,91 \pm 0,07$ & 0,00 \\
\hline
\end{tabular}

*Análise em triplicata 
Alguns fabricantes declaram no rótulo do produto teor de lipídios zero, o que é praticamente impossível, pois o cacau em pó possui certa quantidade de lipídio (de 6 a $12 \%$ ), o leite, ainda que desnatado, pode possuir pequena quantidade de lipídio e, além disso, a maioria dos achocolatados analisados possui vitaminas lipossolúveis, que são extraídas pelo solvente.

Existe certa preocupação por parte dos profissionais da saúde e dos próprios consumidores em relação à ingestão de gorduras. Os achocolatados dietéticos, que são direcionados a um público que tenha necessidades dietoterápicas específicas (diabéticos), possuem alto teor de lipídios em relação aos achocolatados tradicionais. Estes alimentos são "diet" somente em certos açúcares e não são, portanto, "diet" em gorduras. Sendo assim, a ingestão destes alimentos deve ser controlada mesmo pelos diabéticos, principalmente por crianças (em especial as crianças diabéticas), que são grandes consumidores de produtos derivados de cacau e chocolate, pois a ingestão excessiva de lipídios contribui para a obesidade, que está relacionada ao risco de retinopatia nestes indivíduos (Segal, 1992), além de fortemente ligada a coronariopatias, hipertensão, resistência à insulina e câncer (Lachance, 1994; Shils, 2003).

A ingestão de lipídios geralmente não deve exceder $30 \%$ da energia em indivíduos diabéticos. Mais importante, as gorduras saturadas, devido ao seu potencial aterogênico, devem ser restringidas ao máximo de $10 \%$ das necessidades energéticas. As poliinsaturadas também devem ser restringidas abaixo de $10 \%$ e a ingestão de colesterol deve ser mantida abaixo de $200 \mathrm{mg} /$ dia (Mahan, Arlin, 1995; Shils, 2003).
O achocolatado por si só não fornece grandes quantidades de lipídios à dieta, mas dependendo da quantidade ingerida, ele pode ajudar a aumentar a ingestão lipídica e calórica diária, somando-se a outras fontes de lipídios.

\section{Proteína}

A Tabela III mostra o teor de proteínas dos achocolatados analisados e o teor de proteínas declarado nos rótulos.

Os achocolatados dietéticos apresentaram teor de proteínas significativamente maior que os achocolatados tradicionais, devido ao fato de os mesmos apresentarem como um dos edulcorantes o aspartame, que é um éster metílico de dois aminoácidos, a fenilalanina e o ácido glutâmico, ou seja, éster metílico de L-aspartil-Lfenilalanina (Filler, Lewis, 1989; Pivonka, Gunewald, 1990; Cândido, Campos, 1996).

Nos achocolatados tradicionais, a maior parte da proteína provém do leite em pó e do soro de leite em pó.

\section{Cinzas}

A Tabela IV mostra o teor de cinzas dos achocolatados analisados.

Segundo Medeiros e Lannes (1999), o conteúdo de cinzas da torta de cacau (a partir da qual se obtém o cacau em pó) e da torta de cupuaçu é de, aproximadamente, $4 \%$. Na indústria, a torta de cacau pode chegar a $7 \%$ de cinzas. O achocolatado, por se tratar de mistura de pós de diferentes teores de cinzas, pode apresentar teor maior ou menor de cinzas em relação à torta de cacau, sendo

TABELA III - Teor de proteínas dos achocolatados e o declarado nos rótulos

\begin{tabular}{lcl}
\hline Achocolatado & $\begin{array}{c}\text { Teor de proteínas (\%)* } \\
\text { (média } \pm \text { desvio-padrão) }\end{array}$ & $\begin{array}{l}\text { Teor de proteínas declarado nos } \\
\text { rótulos (\%) }\end{array}$ \\
\hline Chocolike & $2,23 \pm 0,01$ & Menor que $1 \mathrm{~g}$ em 25 g de produto \\
Achocolatado Extra & $3,08 \pm 0,03$ & Menor que $1 \mathrm{~g}$ em 25 g de produto \\
Garotada & $2,29 \pm 0,03$ & Menor que $1 \mathrm{~g}$ em 25 g de produto \\
Gold & $11,47 \pm 0,02$ & Menor que $1 \mathrm{~g}$ em 9 g de produto \\
Leo & $1,95 \pm 0,03$ & Menor que $1 \mathrm{~g}$ em 26 g de produto \\
Moc & $2,11 \pm 0,00$ & Menor que $1 \mathrm{~g}$ em 30 g de produto \\
Nescau & $3,21 \pm 0,00$ & $1 \mathrm{~g}$ em 25 g de produto \\
Nescau light & $5,92 \pm 0,05$ & Menor que 1 g em 16 g de produto \\
Nesquik & $4,02 \pm 0,00$ & $1 \mathrm{~g}$ em 25 g de produto \\
Sempre light & $13,29 \pm 0,01$ & 12,6 g em 100 g de produto \\
Toddy & $2,39 \pm 0,03$ & Menor que $1 \mathrm{~g}$ em 25 g de produto \\
\hline
\end{tabular}

*Análise em triplicata 
TABELA IV - Teor de cinzas, umidade e pH das amostras de achocolatados

\begin{tabular}{lccc}
\hline Achocolatado & $\begin{array}{c}\text { Teor de cinzas (\%)* } \\
\text { (média } \pm \text { desvio-padrão) }\end{array}$ & $\begin{array}{c}\text { Teor de umidade (\%) } \\
\text { (média } \pm \text { desvio-padrão) }\end{array}$ & $\begin{array}{c}\text { pH } \\
\text { (média } \pm \text { desvio-padrão) }\end{array}$ \\
\hline Chocolike & $0,93 \pm 0,04$ & $0,37 \pm 0,05$ & $8,12 \pm 0,16$ \\
Achocolatado Extra & $1,15 \pm 0,06$ & $0,55 \pm 0,03$ & $8,06 \pm 0,17$ \\
Garotada & $0,81 \pm 0,04$ & $0,67 \pm 0,02$ & $7,81 \pm 0,18$ \\
Gold & $5,03 \pm 0,06$ & $4,04 \pm 0,08$ & $7,17 \pm 0,13$ \\
Leo & $0,69 \pm 0,05$ & $0,62 \pm 0,01$ & $7,46 \pm 0,09$ \\
Moc & $0,97 \pm 0,08$ & $0,31 \pm 0,03$ & $7,33 \pm 0,07$ \\
Nescau & $1,22 \pm 0,09$ & $2,16 \pm 0,03$ & $6,81 \pm 0,05$ \\
Nescau light & $2,23 \pm 0,03$ & $1,97 \pm 0,01$ & $6,99 \pm 0,01$ \\
Nesquik & $1,55 \pm 0,04$ & $1,65 \pm 0,05$ & $7,17 \pm 0,03$ \\
Sempre light & $5,84 \pm 0,09$ & $4,45 \pm 0,07$ & $7,11 \pm 0,02$ \\
Toddy & $1,16 \pm 0,03$ & $0,37 \pm 0,05$ & $6,96 \pm 0,07$ \\
\hline
\end{tabular}

*Análises em triplicata.

geralmente menor devido a grandes quantidades de açúcar. Lannes e Medeiros (2003) encontraram valores de $2,43 \%$ de cinzas (antes da instantaneização por spraydryer) e $5,10 \%$ de cinzas (após instantaneização) em achocolatados de cupuaçu. Esse aumento se deu, provavelmente, pelo acréscimo de leite para realização da instantaneização. As cinzas provêm basicamente do cacau em pó e derivados, do soro de leite em pó e do leite em pó. Os achocolatados dietéticos apresentaram teor elevado de cinzas, em comparação com os demais achocolatados, por apresentarem maior quantidade de cacau em pó e derivados e, provavelmente, maior quantidade de ingredientes lácteos. Quanto maior é a quantidade de cacau em pó e derivados e ingredientes lácteos, provavelmente maior será o teor de cinzas do produto.

\section{Umidade}

A Tabela IV mostra o teor de umidade dos achocolatados analisados.

Um teor maior ou menor de umidade dos achocolatados depende diretamente da umidade dos ingredientes e/ou do processamento do achocolatado. De acordo com especificações técnicas das indústrias, o cacau em pó possui teores de umidade variando de $2,5 \%$ a $4,5 \%$; o teor de umidade do aspartame pode chegar a $4,5 \%$. A umidade dos achocolatados, na sua maior parte, provém do cacau em pó e derivados e do aspartame, já que outros ingredientes contribuem muito pouco com esta característica, devido às suas propriedades de baixa higroscopicidade. Isso explica o fato de os achocolatados dietéticos terem apresentado teor de umidade maior, já que os mesmos, provavelmente apresentam quantidades de cacau em pó e derivados maiores que os tradicionais. Além disso, eles são os únicos que contêm aspartame em sua formulação.

O processamento de achocolatados por aglomeração (processo que forma aglomerados de pó com o intuito de melhorar a molhabilidade e outras propriedades físicas, como compactação e fluxo) pode deixar no produto umidade maior. O produto pode sair do equipamento com umidade final de 2 a 4\% ( Gea Niro Inc, 2004; Production and Quality, 2004). Os achocolatados Nescau, Nescau light e Nesquik, provavelmente são produzidos por este método, o que explica teor de umidade maior nesses achocolatados.

\section{pH}

A Tabela IV mostra o $\mathrm{pH}$ das amostras de achocolatado analisadas.

$\mathrm{O}$ pH do achocolatado depende do grau de alcalinização que o cacau possui e da quantidade e acidez do soro de leite utilizado. Em geral, o grau de alcalinização de pó de cacau para achocolatados e bebidas achocolatadas feito na indústria leva a um $\mathrm{pH}$ em torno de 7,1. O pH do soro de leite em pó pode variar de 6,5 a 6,7.

\section{Teobromina e alcalóides totais}

Existe interesse crescente entre os profissionais da saúde no conteúdo de metilxantinas nos alimentos (Zoumas et al., 1980).

A teobromina juntamente com a cafeína e a teofilina são as metilxantinas mais presentes na natureza. São alcalóides naturais, largamente ingerido, e apresentam diversos efeitos farmacológicos em humanos (Kumazawa et al., 1999; Stavric, 1988). 
A Figura 1 mostra a estrutura química da teobromina.<smiles>Cn1cnc2c1c(=O)[nH]c(=O)n2C</smiles>

Teobromina

3,7-diidro-3,7-dimetil-1 $H$-purino-2,6-diona

FIGURA 1 - Estrutura química da teobromina.

De acordo com Matissek (1997), a cafeína é encontrada no cacau em pequenas quantidades, podendo variar, de acordo com Zoumas et al. (1980), de 0,08 a 0,35\%. A teofilina é encontrada em menor quantidade. $\mathrm{O}$ alcalóide em maior quantidade no cacau é a teobromina, podendo variar de 1,46 a 2,66 \% (Zoumas et al., 1980; Lannes, 1997).

A importância das metilxantinas advém do fato de as mesmas poderem apresentar ação estimulante do Sistema Nervoso Central (Kuribara, 1993; Kuribara et al., 1992), o que pode ser desejável em alguns casos, como em adolescentes e jovens em fase escolar, mas pode ser indesejável em bebês e crianças, causando-lhes insônia e irritação, já que são mais suscetíveis. Por isso, se faz necessário controle da ingestão de produtos derivados do cacau, como os achocolatados, as bebidas achocolatadas, os biscoitos de chocolate, as barras de chocolate, entre outros, principalmente por parte das crianças.

Além disso, há recente interesse centrado na potencial toxicidade reprodutiva da teobromina, pois ela atravessa a barreira hemato-encefálica, podendo, supostamente, induzir mal-formação fetal, afetando os genes vitais em desenvolvimento. $\mathrm{O}$ feto em desenvolvimento não desenvolveria enzimas para a destoxificação dessa metilxantina. Por esta e outras razões, a presença de teobromina no cacau limita o seu potencial como alimento nutritivo (Eteng et al., 1997).

A Tabela V mostra o teor de teobromina das amostras de achocolatado analisadas.

Os achocolatados com maiores teores de teobromina foram os dietéticos e o "light" devido à suposta maior quantidade de cacau em pó e derivados que os tradicionais.

Zoumas et al. (1980) analisaram o teor de teobromina em alguns alimentos derivados do cacau, como a massa de cacau, barras de chocolate, chocolate ao leite e no próprio cacau comercial e encontraram as concentrações de: 0,82 a $1,73 \%$ para massa de cacau, 0,36 a $0,63 \%$ para chocolate recheado, 0,14 a $0,19 \%$ para chocolate ao leite e 1,46 a $2,66 \%$ para cacau comercial.

Lannes (1997) encontrou teores de teobromina em coberturas brasileiras de chocolate ao leite e meio amargo que variaram de 0,2 a $0,4 \%$ e teores de alcalóides totais de 0,6 a 1,2\%. Em barras de chocolate ao leite de procedência alemã, encontraram-se teores de teobromina que variaram de 0,21 a $0,28 \%$ e teores de alcalóides totais de 0,64 a $0,86 \%$.

TABELA V - Teor de teobromina e alcalóides totais das amostras de achocolatado

\begin{tabular}{lcc}
\hline Achocolatado & $\begin{array}{c}\text { Teor de teobromina (\%)* } \\
\text { (média } \pm \text { desvio-padrão) }\end{array}$ & $\begin{array}{c}\text { Teor de alcalóides totais (\%) } \\
\text { (média } \pm \text { desvio-padrão) }\end{array}$ \\
\hline Chocolike & $0,14 \pm 0,00$ & $0,41 \pm 0,00$ \\
Achocolatado Extra & $0,16 \pm 0,00$ & $0,47 \pm 0,00$ \\
Garotada & $0,14 \pm 0,00$ & $0,41 \pm 0,00$ \\
Gold & $0,52 \pm 0,00$ & $1,58 \pm 0,00$ \\
Leo & $0,05 \pm 0,00$ & $0,14 \pm 0,00$ \\
Moc & $0,10 \pm 0,00$ & $0,31 \pm 0,00$ \\
Nescau & $0,19 \pm 0,00$ & $0,55 \pm 0,02$ \\
Nescau light & $0,25 \pm 0,00$ & $0,74 \pm 0,01$ \\
Nesquik & $0,21 \pm 0,00$ & $0,63 \pm 0,00$ \\
Sempre light & $0,39 \pm 0,01$ & $1,18 \pm 0,01$ \\
Toddy & $0,12 \pm 0,00$ & $0,35 \pm 0,00$ \\
\hline
\end{tabular}

*Análises em triplicata 


\section{CONCLUSÕES}

Através das análises químicas dos achocolatados pode-se perceber que os ingredientes que mais influenciam nas propriedades químicas dos achocolatados são o cacau em pó e derivados e os ingredientes lácteos. Destaque é dado aos resultados obtidos da análise de teobromina, cujos valores nos informam a situação dos achocolatados consumidos em função deste importante alcalóide, sendo que os produtos "diet" e "light" possuem quantidades maiores que os produtos normais.

\section{ABSTRACT}

\section{Chocolate drink powders: chemical analysis}

Some chemical properties of chocolate drink powders from Brazilian market, such as lipid, protein, ashes, moisture, $\mathrm{pH}$, theobromine and total alkaloids content of the samples were evaluated. These properties are mainly influenced by cocoa powder content and by dairy products, such as milk powder and whey. A comparison among the brands, emphasizing their strong differences, when existing, among diet (without sugars) and light (low sugar) and the standard brands was made.

UNITERMS: Chocolate drink powder. Nutritional information. Chemical properties.

\section{REFERÊNCIAS BIBLIOGRÁFICAS}

BRASIL. Leis, decretos, etc. Portaria n.29/98 da Agência Nacional de Vigilância Sanitária do Ministério da Saúde. Disponível em: $<$ http://www.anvisa.gov.br $>$. Acesso em: 24 abr. 2004.

CAFFEINE: a healthy habit? Environ. Nutr. Newsl., New York, v. 2, n.6, p.1-2, 1979.

CÂNDIDO, L. M. B; CAMPOS, A. M. Alimentos para fins especiais: dietéticos. São Paulo: Livraria Varela, 1996. $423 \mathrm{p}$.

CARVALHO, C. R. L.; MANTOVANI, D. M. B.; CARVALHO, P. R. N. Análises químicas de alimentos. Campinas: Instituto de Tecnologia de Alimentos, 1990. 10p. (Manual Técnico).
EDUARDO, M. F.; BAVUTTI, H. R. F. Determinação e comparação do teor de lipídios em alimentos dietéticos e não-dietéticos pelo método de Soxhlet. In: ENCONTRO ESTADUAL DE FARMACÊUTICOS E BIOQUÍMICOS, 11; CONGRESSO CATARINENSE DE FARMACÊUTICOS E BIOQUÍMICOS, 9; ENCONTRO DE FARMACÊUTICOS DO MERCOSUL, 3., Florianópolis, 2002. Resumos. Florianópolis: SINDIFAR, 2002. CD ROM.

ETENG, M. U.; EYONG, E. U.; AKPANYUNG, E. O.; AGIANG, M. A.; ARENU, C. Y. Recent advances in caffeine and theobromine toxicities: a review. Plant Foods Hum. Nutr., Dordrecht, v.3, n. ?, p.231-243, 1997.

FILLER JUNIOR, L. J.; LEWIS, D. S. Aspartame metabolism in normal adults: phenylketonuric heterozygotes and diabetic subjects. Diabetes care, New York, v.12, n.1, suppl. 1, p.67-73, 1989.

GEA NIRO INC. Rewet agglomeration. 2004. Disponível no site: <http://www.niroinc.com/html/drying/ rewet_agglomerateor.html>. Acesso em : 30 abr. 2004.

HURREL, R. F.; REDDY, M. B.; DASSENKO, S. A; COOK, J. D.; SHEPHERD, D. Ferrous fumarate fortification of a chocolate drink powder. Br. J. Nutr., London, v. 65, p.271-283, 1991.

INSTITUTO ADOLFO LUTZ. Normas analíticas do Instituto Adolfo Lutz. 2.ed. São Paulo, 1976. v.1, p.24.

KUMAZAWA, T.; SENO, H.; PEN-LEE, X.; ISHII, A.; SUZUKI, K. W.; SATO, K.; SUZUKI, O. Extraction of methylxanthines from humans body fluids by solid-phase microextraction. Anal. Chim. Acta, Amsterdam, v.387, n.1, p.53-60, 1999.

KURIBARA, H. Enhancement of the behavioral toxicity induced by combined administration of ethanol with metilxanthines: evaluation by discrete avoidance in mice. J. Toxicol. Sci., Tokyo, v. 18, n.2, p.95-201, 1993.

KURIBARA, H.; ASAHI, T.; TADOKORO, S. Behavioral evaluation of psycho-pharmacological and psychotoxic actions of methylxanthines by ambulatory activity and discrete avoidance in mice. J. Toxicol. Sci., Tokyo, v. 17, n.2, p.81-90, 1992. 
LACHANCE, P. A. Scientific status summary. Human obesity. Food Technol., Chicago, v.48, n.2, p.127-138, 1994.

LANNES, S. C. S. Estudo das propriedades fisicoquímicas e de textura de chocolates. São Paulo, 1997. 175p. (Tese de Doutorado. Faculdade de Ciências Farmacêuticas. Universidade de São Paulo).

LANNES, S. C. S.; MEDEIROS, M. L. Processamento de achocolatado de cupuaçu por spray dryer. Rev. Bras. Ciênc. Farm., São Paulo, v.39, n.1, p.115-123., 2003.

MAHAN, L.K.; ARLIN, M. T. Alimentos, nutrição e dietoterapia. 8. ed. São Paulo: Editora Roca, 1995.957p.

MATISSEK, R. Evaluation of xanthine derivatives in chocolate - nutricional and chemical aspects. $Z$. Lebensm. Unters. Forsch., Munich, v. 205, n.3, p. 175184, 1997.

MEDEIROS, M. L.; LANNES, S. C. S. Torta de cupuaçu: composição e utilização. Rev. Bras. Ciênc. Farm., São Paulo, v.35, supl.1, p.118, 1999. [TBF53].

NINFALI, P.; GIORGINI, S.; BIAGO Hi, E.; FIORUCCI, C.; PALMA, P.; MANGINI, S.; TAVERNA, D. Flavonoids in milk and dark chocolate: possible strategy for the preparation of fortified chocolate. Ingredienti Alimentari, v. 1, n.5, p.6-10, 2002.

OMOBUWAJO, T. O.; BUSARI, O. T.; OSEMWEGIE, A. A. - Thermal agglomeration of chocolate drink powder. J. Food Eng., London, v.46, p.73-81, 2000.

PIVONKA, E. E.; GRUNEWALDF, K. K. Aspartame or sugar - sweetened beverages: effects on mood in young women. J. Am. Diet. Assoc., Chicago, v.90, n.2, p.250253, 1990.
PRODUCTION AND QUALITY. Technologies for manufacturing milk powders. 2004. Disponível em: $<$ http:/ www.usdec.org/files/pdfs/USMP15-22.pdf > . Acesso em: 30 abr. 2004.

REIN, D.; PAGLIERONI, T. G.; PEARSON, D. A.; WUN, T.; SCHMITZ, H. H., GOSSELIN, R.; KEEN, C. L. Cocoa and wine polyphenols modulate platet activation and function. J. Nutr., Philadelphia, v. 130, n.8, p.2120S-2126S, 2000.

SCHETTY, O.; ANKER, P.; JUNKER, E.; KLEINERT, J. - Schweizerisches lebensmittelbuch. Métodos 36C/17 e 36C/04. 5.ed., 1969.

SEGAL, N. Obesity as a risk factor in diabetic retinopathy. Oftalmologia, v.1, p.35-38, 1992.

SHILS, M. E.; OLSON, J. A.; SHIKE, M.; ROSS, A.C. Tratado de nutrição moderna na saúde e na doença. São Paulo: Manole, 2003. v.2, 2106p.

STAVRIC, B. Methylxanthines: toxicity to humans III. Theobromine, paraxanthine and the combined effects of methylxanthines. Food Chem. Toxicol., Oxford, v.26, n.8, p.725-733, 1988 .

VARNAM, A.H.; SUTHERLAND, J. P. Bebidas: tecnología, química y microbiología. Zaragoza: Ed.Acribia, S.A, 1997. v.2, p. 289-294 .

YING W.; VINSON, J. A; ETHERTON, T. D.; PROCH, J.; LAZARUS, S. A.; KRIS-ETHERTON, P. M. Effects of cocoa powder and dark chocolate on LDL oxidative susceptibility and protaglandin concentration in humans. Am. J. Clin. Nutr., Bethesda, v. 74, p. 596-602, 2001.

ZOUMAS, B. L.; KREISER, W. R.; MARTIN, R. A. Theobromine and caffeine content of chocolate products. J. Food Sci., Tokyo, v. 45, p. 314-316, 1980.

Recebido para publicação em 14 de maio de 2004. Aceito para publicação em 13 de setembro de 2004. 